\title{
REFLECTION
}

\section{BiDil: Assessing a Race-Based Pharmaceutical}

Howard Brody, $M D, P b D^{1}$

Linda M. Hunt, $P b D^{2,3}$

'Department of Family Practice and the Center for Ethics and Humanities in the Life Sciences, Michigan State University, East Lansing, Mich

${ }^{2}$ Department of Anthropology, Michigan State University, East Lansing, Mich

${ }^{3}$ Center for Ethics and Humanities in the Life Sciences, Michigan State University, East Lansing, Mich
Conflicts of interest: none reported

\section{CORRESPONDING AUTHOR}

Howard Brody, MD, PhD Institute for the Medical Humanities University of Texas Medical Branch 301 University Blvd

Galveston, TX 77555-1311

habrody@utmb.edu

\begin{abstract}
Isosorbide and hydralazine in a fixed-dose combination (BiDil) has provoked controversy as the first drug approved by the Food and Drug Administration marketed for a single racial-ethnic group, African Americans, in the treatment of congestive heart failure. Family physicians will be better prepared to counsel their patients about this new drug if they understand a number of background issues. The scientific research leading to BiDil's approval tested the drug only in African American populations, apparently for commercial reasons, so the drug's efficacy in other populations is unknown. Race as a biological-medical construct is increasingly controversial; BiDil offers a good example of how sociocultural factors in disease causation may be overlooked as a result of an overly simplistic assumption of a racial and hence presumed genetic difference. Past discrimination and present disparities in health care involving African American patients are serious concerns, and we must welcome a treatment that promises to benefit a previously underserved group; yet the negative aspects of BiDil and the process that led to its discovery and marketing set an unfortunate precedent. Primary care physicians should be aware of possible generic equivalents that will affect the availability of this drug for low-income or uninsured patients.
\end{abstract}

Ann Fam Med 2006;4:556-560. DOI: 10.1370/afm.582.

\section{INTRODUCTION}

$\Gamma$ amily physicians have no doubt been approached by their African American patients with congestive heart failure (and perhaps with other heart diseases), asking about the new "for blacks only" medicine, isosorbide dinitrate and hydralazine hydrochloride (BiDil). Perhaps patients of other ethnic backgrounds have also asked their physicians about this drug. The media has covered the drug approval process extensively before and after a Food and Drug Administration (FDA) advisory committee recommended approval of $\mathrm{BiDil}$ for the specific indication of congestive heart failure in African Americans-the first drug to be approved for a single racial group. ${ }^{1,2}$

Advising our patients requires that we understand the science behind this new pharmaceutical development. It also requires that we be fully aware of the economic, social, cultural, and ethical issues lurking in the background of this purported discovery. In this article, we provide an overview of these issues and try to place the decision as to whether to recommend or prescribe BiDil in context for family physicians.

\section{SCIENTIFIC BACKGROUND}

Understanding the science undergirding BiDil requires a brief historical review, as well as a discussion of the scientific data. African American patients are more likely to die of heart failure compared with whites. Explanations are wide-ranging and include delay in diagnosis and treatment $_{;}$limited access to coronary care ${ }_{i}$ high prevalence of high-risk individuals with hypertension, diabetes, and dyslipidemia $;$ and such related 
behavioral risk factors as physical inactivity and smoking. ${ }^{3}$ One explanation focuses on impaired bioavailability of nitric oxide, which is thought to contribute to the structural remodeling of the left ventricle that increases the rate of death and complications. It has been proposed that African American patients may have a disproportionately lower nitric oxide bioavailability. Isosorbide acts as a nitric oxide donor and hydralazine as an antioxidant, and so together they might ameliorate the long-term effects of heart failure. ${ }^{4}$

A combination of isosorbide and hydralazine (160 $\mathrm{mg}$ and $300 \mathrm{mg}$ total daily dose, respectively) was compared with enalapril $(20 \mathrm{mg})$ in the second Vasodilator-Heart Failure Trial. ${ }^{5}$ Mortality at 2 years was significantly lower in the enalapril arm. A later retrospective review of those data, however, found that white patients had disproportionate benefit from enalapril, whereas the subset of African American patients appeared to receive substantially more benefit from the isosorbide-hydralazine therapy. ${ }^{6}$ As of this point, no one had yet tested the hypothesis that isosorbide and hydralazine, added to a regimen that already included an angiotensin-converting enzyme (ACE) inhibitor, might provide benefit to patients with congestive heart failure.

The African American Heart Failure Trial (A-HeFT) was set up by the commercial sponsor, NitroMed, to test this hypothesis. Only African American patients were enrolled in the trial. About 1,000 patients were randomized to a fixed-dose combination of isosorbide and hydralazine (target daily dose, $120 \mathrm{mg}$ and 225 $\mathrm{mg}$, respectively) or placebo added to their existing medications (69\% were on ACE inhibitors at baseline). Follow-up was planned for 18 months, but the study was stopped early (mean duration of follow-up, 10 months) because of excess mortality in the placebo group (54 vs 32 patients; $43 \%$ relative risk reduction; number needed to treat $=25$ ). The composite outcome score (based on death, hospitalization, and quality of life) was significantly better in the drug group. ${ }^{4}$

Based on these impressive findings, an FDA advisory panel recommended on June 16, 2005, that BiDil be approved specifically for the treatment of heart failure in African American patients. Because A-HeFT enrolled only African American subjects, the question of whether other patients might also benefit from adding isosorbide and hydralazine to their existing drug regimens for congestive failure remains unanswered at this time. ${ }^{7}$

\section{Race as a Scientific Construct}

As we begin to address the broader issues that frame the scientific discussion of BiDil's uses and limits, we inevitably encounter the current debate over the use of race in medicine and medical science. This controversy may seem strange to many physicians, but it is currently a hotly debated issue amongst social and genetic scientists. For example, 2 prominent research journals recently devoted special issues to the controversy. 8,9 We will touch upon only a few highlights.

It has for some time been taken for granted that racial categories are of use to the physician in assessing the risks of various diseases. The latest genomic science has, however, failed to provide much support for our intuitions about racial categories in medicine. It has been shown generally that there is more genetic diversity within a so-called "racial" cohort than there is difference between 2 such cohorts. Nor does the human genome, in general, show the sorts of radical discontinuities among different racial groups that our commonplace intuitions would call for; instead, we see much more evidence of gradual blending. Craig Venter, who helped produce the first map of the human genome, commented regarding BiDil, "It is disturbing to see reputable scientists and physicians even categorizing things in terms of race... There is no basis in the genetic code for race." ${ }^{\prime 10}$ Given the new genomic science, we must at least entertain the hypothesis that our intuitions were shaped, not by true empirical data, but in large part by vestiges of now-discredited biological theories of race, while acknowledging that most physicians today are not consciously racist nor intend racial discrimination.

A recent review of genomic science by a group of social scientists offered the conclusions that we must continue to do research on race in medicine, because whatever its biological basis (or lack of same), race remains a very important social construct, and as such, it has tremendous power to influence health and illness. ${ }^{11}$ For example, some heart diseases may afflict African Americans more than whites because of the chronic stresses associated with being a member of a minority group rather than because of genetic factors. Simply eliminating race as a variable in medical research would undermine our ability to detect these factors and can therefore hardly be helpful in reducing the serious disparities that remain a problem in American medicine. At the same time we must actively avoid the intellectual trap of assuming that disease incidence disparities among racial or ethnic groups are rooted in genetic differences. We also must not assume that small effects may be attributable to sociocultural variables and that large effects always signal a biologic or genetic basis.

In the face of recent genomic data, some have felt the need to try to preserve our old intuitions and to rescue a concept of race that is, on the one hand, clearly biologically grounded, but on the other hand, avoids invidious discrimination. According to the view 
called "geographic race," self-ascribed racial groups tend to correspond reasonably well with the continent from which one's ancestors came. Continent of origin (and hence race) might then be a useful proxy indicator of important clusters of genetic traits. Data have been derived from haplotype mapping that appear at first glance to support such a view. ${ }^{12}$ These findings, however, remain highly controversial and have been soundly challenged in terms of their practical generalizability and biomedical importance. . $^{13,14}$

\section{BiDil and Past Invidious Discrimination}

Many African American patients perceive that their community has historically been subjected to invidious racial discrimination by a white-dominated medical system. Whereas the infamous Tuskegee study has been the lightning rod for much of this sentiment, it is important to recall that many other events, both before and after Tuskegee, all served to create a wellgrounded impression that the medical care received by African Americans fell short of what was available to white patients. ${ }^{15}$ Even today, many life-extending procedures are used much less often among African American patients than among whites despite an absence of medical contraindications. ${ }^{16}$

In the face of this unfortunate history, it is hard to avoid the conclusion that the emergence of an effective drug that is somehow "for blacks only" is a long overdue bit of poetic justice. Whatever one might think of the scientific pathway that led to BiDil being approved specifically for African Americans, or of the other issues we will review below, the mere fact that a new drug seems to offer hope to African Americans with a serious chronic disease is a cause for celebration. It is very important that we not allow other legitimate concerns to make us appear insensitive to this unfortunate history of discrimination in health care.

\section{THE ECONOMICS OF BIDIL}

The great majority of clinical trials of drugs in the United States are now funded by the pharmaceutical industry. ${ }^{17}$ The average major drug firm spends 2 to 3 times as much on marketing as it does on research and development. ${ }^{18}$ There is increasing evidence that all too often the industry allows the marketing tail to wag the research dog. ${ }^{19}$ Unfortunately, BiDil provides several examples of this trend.

The African American cardiologists who participated in the BiDil study had to walk a fine line-avoiding too close an alliance with for-profit interests could easily have led to turning down a rare opportunity to do important research on heart disease in African American patients. As a rule, these investigators have been notably balanced and candid in assessing both the pros and cons of the research and its broader implications.

Nevertheless, BiDil appears to be in large part a creature of marketing. The decision to seek a patent for a race-specific application extended the patent protection $\mathrm{BiDil}$ will enjoy by 13 years. ${ }^{11} \mathrm{BiDil}$ reportedly will be marketed at $\$ 1.80$ per pill (with means-based discounts offered by the company), roughly 4 to 7 times the cost of generic isosorbide plus hydralazine. ${ }^{2}$ The African American Heart Failure Trial (A-HeFT) was designed to study a formulation of the 2 medications that did not match available generic doses (37.5 mg of hydralazine, instead of the most common available generic forms, 25 or $50 \mathrm{mg}$ ). If physicians, trying to save money for the patient or the insurer, attempt to substitute a generic dose, they are open to criticism if the patient does poorly, because they have failed to match precisely the dosage regimen that has been validated in a major controlled trial.

The present defenders of $\mathrm{BiDil}$ have admitted that race is a poor scientific prop upon which to base the efficacy of a drug. They insist that eventually we will find the true genetic basis of the differential response to this medication; at that later date, some form of pharmacogenetic screening test will presumably identify all the patients, of whatever race, who will benefit from the drug. In the meantime, of course, they contend that we should not withhold an efficacious drug from a subgroup known to benefit, regardless of how crude a surrogate marker race may be.

What would be the financial incentive for the manufacturer to undertake the next round of pharmacogenetic research? Companies seek to expand, not to contract, the markets for their drugs. Under the present marketing structure, the company can sell BiDil to African American patients; depending on how well the drug performs in practice, the company can also count on a certain amount of off-label prescribing as physicians elect to try it for patients of other races. To what extent would the identification of a specific genetic trait, correlated with positive therapeutic response, be likely to expand that market? As long as there is some probability that the results of that further research could cause the market to shrink, even if by a small amount, there is every incentive for the company to decline to undertake that research.

In sum, $\mathrm{BiDil}$ is on the scene today mostly in answer to the question of how a company could generate a profit and much less in answer to the question of which drug would best help which group of patients and why. Family physicians might be leery of offering too much support to this so-called way of "advancing" medical knowledge. 
Reinvigorating Race as a Medical Category

We have already reviewed the reasons as to why race, seen as a biological variable rather than as a social construct, is or should be falling out of favor in medical science. Given the history of how race has been used to justify differential treatment, almost always to the detriment of society's less powerful groups, we have good reason to welcome this development, even though it originates in a scientific understanding of genomics rather than in an urge for social reform.

By contrast, anything that seems likely to cement further the notion of race as a real biological variable in medicine, in addition to a marker of importance in diagnosis and therapeutics, might appear to be a retrogression. Despite the comforting claims that $\mathrm{BiDil}$ is about race only as a matter of temporary convenience, the popularity of this drug is almost certain to prompt the general impression that race works as a medical category. As Kahn has stated, "The role of the federal legal and regulatory system in producing BiDil as an ethnic drug is especially important because it lends the imprimatur of the state to the use of race as a biological category." ${ }^{\prime 10, p 33}$

Perhaps any negative fallout from rediscovering race as a biological category will be readily contained in a society that is now better attuned to the dangers of racism. Or perhaps these ideas may have serious negative consequences that extend beyond the good that BiDil might do for sufferers from congestive heart failure. Past history leads one to tread warily along such a path.

\section{Ignoring Nongenetic Contributors to Disease}

Family physicians, well schooled in the biopsychosocial model of health, ought especially to be concerned about an approach to research that de-emphasizes the search for social and cultural factors in disease. ${ }^{11,20}$ Advocates of BiDil have promoted the notion that because African Americans die of heart failure at twice the rate as whites, such a great difference cannot be explained by sociocultural variables alone and must reflect underlying genetic differences.

Kahn has effectively questioned this entire line of reasoning. ${ }^{10}$ First, the 2:1 ratio of deaths among African Americans, a statistic used widely to raise investor capital for NitroMed and to secure political support for BiDil, is derived from older data and looks only at people who are younger than 75 years. If one considers newer data among all age-groups, the ratio appears to be closer to $1.1: 1$. It is still true that African Americans tend to die of heart failure at younger ages than whites, and these data should not excuse us from continuing to battle the serious health disparities we know to exist. But the much-cited 2:1 ratio turns out to be highly questionable.
Second, regardless of the true ratio, the role of genetics in explaining the difference remains an untested hypothesis. For example, hypertension, one of the major risk factors for congestive heart failure, is more common within the African American community; and chronic social stress has been implicated as a possible contributor to the development of hypertension. Diet, exercise, and other environmental variables are also possible mediators. ${ }^{3,11}$

There is a danger that the apparent success of BiDil will lead to a further de-emphasis of research into these social and environmental contributors to disease, while all the research funding is devoted to possible genetic bases. We already have seen a major shift in research funding in the United States as a result of the heavy influence of the pharmaceutical industry. A possibly highly effective nondrug treatment for a life-threatening disease is today less likely to receive research support than a slightly effective drug therapy for a minor lifestyle condition where a lucrative market exists. The BiDil experience is likely to cause this disparity in research funding to grow.

\section{Prescribing Issues}

For suitable patients with heart failure and on optimal doses of other drugs, some might urge that we prescribe BiDil specifically for those who can afford it as a way to reward the company for launching research specifically aimed at reducing health disparities on behalf of African Americans. We anticipate that the company will launch a publicity campaign among the African American community to make this case.

For patients unable to afford an expensive brandname drug, or for family physicians less impressed with the scientific approach that the BiDil research represents, it is important to consider possible lowercost generic options. One could, or instance, prescribe isosorbide $20 \mathrm{mg}$ and hydralazine $25 \mathrm{mg} 3$ times daily, and titrate as tolerated to a ceiling dose of $40 \mathrm{mg}$ of isosorbide and $75 \mathrm{mg}$ of hydralazine 3 times daily- the same target dose used in the A-HeFT trial, which was achieved by about two thirds of the subjects. ${ }^{4}$ Eventually using a 40 -mg isosorbide tablet and 25-mg plus a 50-mg dose form of hydralazine could require that the patient take 3 pills 3 times a day, as compared to 2 BiDil 3 times a day. In either case compliance will be a difficult issue with 3 -times-a-day dosing. But patients need to be aware that the benefits seen in A-HeFT should be readily achieved with a cheaper dosage form.

In counseling patients and community groups, clinicians need to place BiDil in its proper context. The medication appears to offer real benefits for some patients. Until more research is done, we will not know what population groups in addition to African 
Americans might enjoy those benefits. The family medicine community ought to encourage continued action to reduce health disparities, to promote research that addresses the psychological and social contributors to ill health alongside the biological factors, to propose reforms so that future pharmaceutical studies will be driven more by science and less by marketing, and generally to be skeptical of future claims for race-based therapeutics.

To read or post commentaries in response to this article, see it online at http://www.annfammed.org/cgi/current/full/4/6/556.

Key words: Minority groups; heart failure, congestive; genetic predisposition to disease; delivery of health care; health services research; communication

Submitted November 19, 2005; submitted, revised, January 31, 2006; accepted February 17, 2006.

\section{References}

1. Saul S. F.D.A. approves a heart drug for African-Americans. New York Times. June 18, 2004:C2.

2. Saul S. Maker of heart drug intended for blacks bases price on patients' wealth. New York Times. July 8, 2005:C3.

3. Clark LT, Ferdinand KC, Flack JM, et al. Coronary heart disease in African Americans. Heart Dis. 2001;3:97-108.

4. Taylor AL, Ziesche S, Yancy C, et al. Combination of isosorbide dinitrate and hydralazine in blacks with heart failure. $N$ Engl J Med. 2004;351:2049-2057

5. Cohn JN, Johnson G, Ziesche S, et al. A comparison of enalapril with hydralazine-isosorbide dinitrate in the treatment of chronic congestive heart failure. N Engl J Med. 1991;325:303-310.
6. Carson P, Ziesche S, Johnson G, Cohn JN. Racial differences in response to therapy for heart failure: analysis of the vasodilatorheart failure trials. Vasodilator-Heart Failure Trial Study Group. J Card Fail. 1999;5:178-187.

7. Bloche MG. Race-based therapeutics. N Engl J Med. 2004;351: 2035-2037.

8. Anderson NB, Nickerson KJ. Genes, race, and psychology in the genome era: an introduction. Am Psychol. 2005;60:5-8.

9. Special Issue: Genetics for the human race. Nat Genet 2004;36: S1-S60.

10. Kahn J. How a drug becomes "ethnic": law, commerce, and the production of racial categories in medicine. Yale J Health Policy Law Ethics. 2004;4:1-46.

11. Sankar P, Cho MK, Condit CM, et al. Genetic research and health disparities. JAMA. 2004;291:2985-2989.

12. Tang H, Quertermous T, Rodriguez B, et al. Genetic structure, selfidentified race/ethnicity, and confounding in case-control association studies. Am J Hum Genet. 2005;76:268-275.

13. Cooper RS, Kaufman JS, Ward R. Race and genomics. N Engl J Med. 2003;348:1166-1170

14. Jorde LB, Wooding SP. Genetic variation, classification and 'race'. Nat Genet. 2004;36:S28-33.

15. Gamble VN. Under the shadow of Tuskegee: African Americans and health care. Am J Public Health. 1997;87:1773-1778.

16. Institute of Medicine. Unequal Treatment: Confronting Racial and Ethnic Disparities in Healthcare. Washington, DC: National Academy Press; 2003.

17. Bodenheimer T. Uneasy alliance--clinical investigators and the pharmaceutical industry. N Engl J Med. 2000;342:1539-1544.

18. Reinhardt UE. Perspectives on the pharmaceutical industry. Health Aff (Millwood). 2001;20:136-149.

19. Petersen M. Madison Avenue plays growing role in drug research. New York Times. November 22, 2002:A1.

20. Brody $\mathrm{H}$. The validation of the biopsychosocial model. J Fam Pract. 1990;30:271-272. 